\title{
NOTAS SOBRE A FILOSOFIA CONCRETA DO INÍ́CIO DO SÉCULO XX ${ }^{1}$
}

\author{
Leandro Neves Cardim (UFPR) ${ }^{2}$ \\ leandronevescardim@gmail.com
}

Resumo: Trata-se, para nós, de nos situar junto à filosofia de Merleau-Ponty para fazer surgir, em contraste com o comportamento teórico denominado por ele de "pequeno racionalismo" do início do século XX, a noção de concreto, a qual mistura em si mesma o fato e a essência, a particularidade e a universalidade. Inicialmente, lembraremos o modo como o filósofo comenta esta postura teórica que reduz tudo o que se pode dizer sobre o mundo àquilo que diz a ciência. Em seguida, insistiremos, mesmo que muito rapidamente, no fato de que tal posição teórica não está distante de uma posição política demasiadamente otimista que não se dá conta do mundo em que ela mesma se manifesta. Segundo Merleau-Ponty, para compreendermos as relações entre o sentido e o não-sentido é preciso formar uma nova ideia de razão: não uma razão que opera agenciando conceitos sobre um fundo de racionalidade inquestionável, mas uma razão que abarca suas origens. $\mathrm{O}$ esboço destas ideias servirá de pano de fundo para estas notas que giram em torno da noção de concreto na filosofia do início do século XX.

Palavras-chave: espírito; concreto; universal; particular.

\section{I - O PEQUENO RACIONALISMO}

\section{Vejamos, inicialmente, o perfil daquilo que Merleau-Ponty chamou de "pequeno racionalismo":}

Dever-se-ia denominar 'pequeno racionalismo' aquele professado ou discutido por volta de 1900 e que consistia na explicação do Ser pela ciência. Supunha uma imensa Ciência já feita nas coisas a que a ci-

\footnotetext{
${ }^{1}$ Recebido: 17-01-2012/Aprovado: 21-03-2012/Publicado on-line: 15-09-2012.

${ }^{2}$ Leandro Neves Cardim é Professor Adjunto da Universidade Federal do Paraná, Curitiba, PR, Brasil.
} 
ência efetiva viria reunir-se no dia de seu acabamento, sem nos deixar coisa alguma para perguntar, pois toda questão sensata teria recebido resposta (MERLEAU-PONTY 1996, 185).

Este estado de pensamento é difícil de ser revivido, apesar de estar bem próximo de nós. Por volta de 1900, era possível encontrar na cultura uma espécie de paradoxo: havia, ao mesmo tempo, um imenso desenvolvimento das ciências, das artes, da filosofia e uma espécie de letargia espiritual. Dado o desenvolvimento de todos estes ramos da cultura, os homens desta época agiam como se a totalidade do real pudesse ser reduzida às relações científicas que saciavam o cientista. Tudo o que pudesse ser dito a propósito de alguma coisa deveria ser dito a partir do discurso científico. A única modalidade de ser possível de ser pensado era aquela espécie que aceita uma definição objetiva através dos métodos da ciência. A razão disto está que em que este "pequeno racionalismo" era expressão de vários mitos. Em particular, Merleau-Ponty analisa dois: o mito das leis da natureza e o mito da explicação científica. $\mathrm{O}$ primeiro situava vagamente as leis da natureza entre as normas e os fatos: pensava-se que segundo estas leis o mundo no qual vivemos era, entretanto, construído. O segundo acreditava poder estender o conhecimento das relações científicas a tudo o que pudesse ser observado, com a intenção de transformar, um dia, a própria existência do mundo em uma proposição idêntica e reconhecível pelo método científico. A esses dois mitos Merleau-Ponty acrescenta todos os outros mitos anexos que proliferavam nos limites das ciências.

O problema está em que por volta de 1900, ao exprimir tal raciocínio, acreditava-se não ceder a nenhuma mitolo- 
gia. ${ }^{3} \mathrm{Na}$ verdade, o europeu culto do início do século XX acreditava falar em nome da própria razão, a qual se confundia com o conhecimento das condições e das causas. Um solo absolutamente seguro poderia ser estabelecido a partir do momento em que uma relação científica pudesse ser reconhecida, o que, no limite, acabaria silenciando todas as questões pertinentes à filosofia e, em particular, as questões sobre a essência e sobre os fatos, as quais deveriam ser respondidas, respectivamente, com as noções de origem e causa. Assim, este "pequeno racionalismo" deve ser compreendido como "a herança de uma tradição que o produziu gradualmente e com a qual nos ocupamos". Ele é o fóssil de um "grande racionalismo" que vigorou no século XVII, o qual já havia perecido no século XVIII "e conservava apenas algumas de suas formas exteriores no racionalismo de 1900" (MERLEAU-PONTY 1996, 186). Podemos imaginar, por contraste, qual é a significação do "grande racionalismo": no que tange ao tópico da relação entre a filosofia e a ciência, não se trata de colocar a ciência contra a filosofia e vice versa, mas, ao contrário, pensar suas relações e seus direitos recíprocos; ou antes, tratava-se, para os pensadores do século XVII, de reconhecer um lugar para a ciência no todo da experiência. Os filósofos desta época não atribuíam à ciência exclusividade, muito menos superioridade em face da filosofia. Para Descartes, Espinosa, Leibniz e Malebranche, por exemplo, a ciência não é a única nem o mais importante discurso sobre o mundo, e isto, mesmo que ela tenha um lugar reservado na consideração da expe-

\footnotetext{
${ }^{3}$ Para um aprofundamento de conjunto deste momento histórico-teórico nomeado por MerleauPonty de "pequeno racionalismo", reenvio aos trabalhos de Frédéric Worms: O momento $1900 \mathrm{em}$ filosofia (WORMS 2004) e A filosofia na França no século XX. Momentos (WORMS 2009).
} 
riência.

Segundo Merleau-Ponty, por volta de 1900, os filósofos e os cientistas estavam de acordo no que diz respeito à redução da experiência a um de seus aspectos. Tudo se passa como se fosse possível impor à existência humana e à humanidade, "certas condições biológicas e materiais" (MERLEAU-PONTY 1996, 286). Aqui, o homem seria interpretado como mais apto do que outros animais e não passaria de um arranjo de componentes materiais físicofisiológicos. Ao mapear a situação teórica de seu tempo, Merleau-Ponty encontra, por um lado, o materialismo, e, por outro, o espiritualismo: o primeiro "biologizava" a humanidade fazendo dela um "episódio da evolução"; a civilização se tornava, em suas mãos, "um caso particular da adaptação". O segundo via algo a mais na humanidade, ele supunha forças superiores em obra no próprio mundo: não se trata de dizer que ele simplesmente derive a humanidade de alguma "fonte sobrenatural". $O$ espiritualista reencontrava uma natureza humana que era a garantia de "eficácia incondicional" de seu método "universalizante". Deste lado da disputa, tudo se passa como se houvesse uma essência humana inabalável que poderia ser governada com receitas teóricas precisas e sem equívocos. Tal essência humana atemporal não era questionada pela filosofia que se abandonava em uma vida universal completamente abstrata. Materialistas e espiritualistas apareciam, assim, nos antípodas um do outro: por um lado, a redução de tudo ao funcionamento do organismo, por outro, a assunção de uma essência da humanidade, uma natureza humana que faria parte do homem assim como a nadadeira faz parte de certas espécies. $\mathrm{O}$ que devemos ressaltar aqui é o fato de que essas perspectivas se excluem mutuamente ao negarem qualquer 
relação entre a materialidade e a espiritualidade. Nada de comunicação entre o exterior e o interior, ao contrário, essas perspectivas estão seguras de não terem nenhum terreno em comum. Para vislumbrarmos o perfil do "pequeno racionalismo" vale acrescentar a esta discordância de horizontes, a concordância de base segundo a qual a última palavra sobre as coisas deve ser proferida pela ciência.

Para Merleau-Ponty, não há como separar a consciências dos valores e a infraestrutura que sustenta tais valores na própria existência. É essa linha divisória que é recusada pela geração imediatamente após a segunda guerra mundial. A indignação de Merleau-Ponty, em particular, se eleva contra este "humanismo sem vergonha" (MERLEAU-PONTY 1996, 287) daqueles que precederam sua geração, ou melhor, daqueles cães de guarda de que falava Nizan. ${ }^{4} \mathrm{O}$ alvo aqui é, sem dúvida, o idealismo do momento 1900, o qual atribuía ao homem a potência do espírito e desconsiderava sua infraestrutura que, na verdade, dá corpo ou encarna o espírito. Imaginava-se que houvesse uma natureza humana eterna, uma humanidade realizada para a qual somente a ciência teria algo de valido a ensinar. Merleau-Ponty não está nem um pouco convencido disto. Ele critica duramente este humanismo predominante de sua época: ater-se à vida do espírito quando no mundo há desorientação e guerra é render-se à abstração. Portanto, contra a racionalidade triunfante da velha escola é preciso reconhecer, como faz a filosofia militante, que a atividade e a passividade são feitas

\footnotetext{
${ }^{4}$ Em Os cães de guarda publicado em 1932, Paul Nizan se atira contra os mandarins da Sorbonne: cães de guarda são aqueles intelectuais que defendem a tradição espiritualista e burguesa. Eles a defendem a qualquer custo. "Bem longe de ser muito comprometido com a ação, os 'cães de guarda' são aqueles que, pretendendo abster-se, serviam, conscientemente ou não, os interesses de certos homens contra outros, ao passo que o papel do filósofo é agir, 'sem interrupção', como diz Nizan" (WORMS 2009, 196).
} 
do mesmo estofo.

\section{II - NOTA SOBRE A SITUAÇÃO POLÍTICA}

Vale à pena retomar a análise feita por Merleau-Ponty da incapacidade da intelectualidade francesa no início do século XX perante a política. Retomemos algumas das conseqüências contidas em um único texto - "A guerra aconteceu" - escrito logo depois da segunda guerra mundial e que nos ajudará a vislumbrar a situação política dos franceses por volta de 1900. Acontece que os franceses ficaram muito surpresos com a explosão da guerra. Por quê?

É que nós não nos guiávamos pelos fatos. Nós havíamos secretamente resolvido ignorar a violência e a infelicidade como elementos da história, porque nós vivíamos num país muito feliz e muito fraco para encará-los. (MERLEAU-PONTY 1966, 245)

O cidadão médio da época era alguém que exprimia um pensamento de característica mista: ao mesmo tempo intelectualista e individualista. O homem pensante encontrava disponível na cultura de seu tempo um universalismo abstrato que não colocava em questão as velhas aquisições; este cidadão justificava suas ações e pensamentos com o aval da razão. Os intelectuais franceses não percebiam que estas características eram particulares, historicamente determinadas e características não de um mundo, mas de certo Estado. $\mathrm{O}$ suporte filosófico desta atitude era uma filosofia otimista do tipo idealista (cartesiana e kantiana) da consciência desencarnada: o "humanismo sem vergonha".

Os racionalistas da velha escola não colocavam em questão os costumes da humanidade constituída, eles se limitavam a fundá-los sobre a razão, sua liberdade era uma liberdade de boa companhia. (MERLEAU-PONTY 1966, 82). 
Já nos anos 40, a Ocupação da França pelos nazistas ensina algo muito importante aos intelectuais: "eles aprenderam a conhecer entre cada consciência e todas as outras esse meio geral onde elas se comunicam e que não havia nome na filosofia de outrora" (MERLEAU-PONTY 1966, 251). ${ }^{5}$ Trata-se, sem dúvida alguma, de apontar para a noção de existência. Desde então, situada neste meio geral a experiência reclamará, por parte de toda a cultura, uma nova interpretação.

Em relação à situação política vigente por volta de 1900 é preciso ressaltar, ainda, que em contraste com uma sociedade povoada por uma população alheia aos problemas humanos e com hábitos derivados de um humanismo solipsista de feição burguesa, os filósofos se depararam com um mundo e com uma sociedade concreta. Agora, é indispensável o reconhecimento de que o acontecimento da guerra implica uma mutação filosófica decisiva. Seria curioso imaginar um espírito racionalista e otimista defender seu país invadido por nazistas. Com a guerra o que se descobriu foi,

\footnotetext{
${ }^{5}$ Simone de Beauvoir diz expressamente: "poucos intelectuais, antes da guerra, tentaram compreender sua época; todos - ou quase todos - aí fracassaram, e o que nós mais estimávamos, Alain, era desconsiderado: nós devíamos assegurar a rendição. Eu sabia, agora, que meu destino estava ligado ao de todos os outros; a liberdade, a opressão, a felicidade e a dor dos homens me concernia intimamente". Ao se referir a Sartre, ela diz que "a guerra operou nele uma decisiva conversão. [...] Sua experiência de prisioneiro o marcou profundamente: ela lhe ensinou a solidariedade; longe de se sentir ofendido ele participava da alegria da vida comunitária" (BEAUVOIR 1963, 15. 16). O próprio Sartre narra, em Março de 1940, sua recusa da "consciência suprema, absoluta e contemplativa", da "atitude contemplativa", da "consciência-refúgio" ("incolor, inodora e sem sabor"). É nesse contexto que a guerra, ou antes, "a guerra como fenômeno mundial", opera nele uma renovação e como que rejuvenescimento de seu pensamento - "foi apenas este ano [1940], por ocasião da guerra, que compreendi a verdade: o caráter não deve se confundir com todas essas máximas-receitas dos moralistas, 'ele é colérico, ele é preguiçoso, etc.'; o caráter é o projeto primeiro e livre de nosso ser no mundo". A consideração da passagem da "liberdade absoluta" a "liberdade desarmada e humana", assim como a conscientização do próprio Sartre de que seu destino era finito, devem encontrar sua gênese aqui: "foi a guerra e Heidegger que me colocaram neste caminho; Heidegger ao me mostrar que não há nada além do projeto através do qual a realidade humana se realiza a si mesma" (SARTRE 1983, 392-393).
} 
nada mais nada menos, a realidade de um ser humano para o qual há uma repercussão de suas ações tanto sobre o mundo exterior quanto sobre si mesmo. Para os cidadãos da época a política dava apenas um tratamento estatístico para o homem, o qual era substituído por um objeto, sendo tratado, consequentemente, com regulamentos gerais e objetivos. Como imaginar uma violência maior do que esta, tratar o homem como um objeto? Quando Merleau-Ponty se refere à polícia, ele diz que, antes da Ocupação, ela existia, mas nenhum intelectual imaginava ter que assumir $\mathrm{o}$ seu posto, esta espécie de problemas não lhes concernia em nada.

Lembro-me de minha perplexidade quando entendi que, subtenente da reserva, eu podia ser requerido pela polícia para ajudar numa prisão e devia mesmo lhe oferecer meus serviços. Foi-nos preciso mudar de opinião. (MERLEAU-PONTY 1966, 255)

Com a guerra, foi possível aprender que as consequências externas das ações humanas atingem todos os seres humanos. A guerra e a Ocupação ensinaram aos franceses pensantes que era preciso mudar de ponto de vista e compreender outrem pelo simples fatos de que vivemos juntos e que, por isto mesmo, há aí algo válido e insubstituível. Nestas circunstancias, os pensadores não podiam mais fazer de conta que a liberdade não passava pelas relações humanas e era transformada pela história. Era preciso afastar a humanidade como uma espécie dada e criar uma humanidade nova.

\section{III - A NOVA IDEIA DE RAZÃO}

"Nascemos na razão como na linguagem", diz o Prefácio de Sentido e não-sentido. Assim como na linguagem em que o 
fundo de silêncio está sempre presente, na razão se passa a mesma coisa, não há razão senão sob um fundo de desrazão. Dito de outro modo: a existência do pensamento racional mais abstrato assim como da linguagem deve exprimir uma espessura, uma densidade, uma obscuridade, enfim, uma historicidade. Porém, não devemos deduzir disto que não haja nada que possa ser dito com alguma certeza. Seja como for, não podemos mais romper os laços dos pensamentos e das falas de seus contextos naturais e históricos. A espécie de razão a que a nova geração de pensadores chegou, depois de ter passado pela contingência fundamental de nossa vida, não é a mesma da tradição materialista e espiritualista. O mesmo Prefácio nos diz ainda que "é preciso que a experiência da desrazão não seja simplesmente esquecida. É preciso formar uma nova ideia de razão". Para Merleau-Ponty, quando estamos em presença de um objeto cultural (romance, poema, pintura, filme), estamos certos de estabelecer um contato com alguma coisa, temos certeza de que alguma coisa é adquirida e logo o objeto cultural começa a emitir sua mensagem ininterrupta. Trata-se, então, de perceber uma "maravilha" que consiste precisamente no fato de que em um mundo contingente "a linguagem e as condutas têm um sentido para aqueles que falam e agem" (MERLEAU-PONTY 1966, 69). O caso aqui é o de uma razão alargada onde Cézanne, por exemplo, realiza com grande risco a expressão e a comunicação. Lembremos que a realização do sentido no mundo só é possível se recusamos o solo de universalidade que caracteriza o horizonte cultural da tradição: "não há mais natureza humana sobre a qual possamos repousar" (MERLEAU-PONTY 1966, 49).

Em 1945, Merleau-Ponty acreditava que o pensador assim como o artista, o político e o homem comum, enfren- 
tavam um grave risco. Tal risco pode ser formulado em forma de uma dúvida: será que aquilo que fazemos e pensamos pode ser levado adiante e ser comunicado a alguém? Essa dúvida é precisamente aquela de Cézanne que mesmo na incerteza dizia que era preciso avançar sem saber se a empreitada obteria sucesso: "é como um passo na bruma, no qual ninguém pode dizer se ele conduz a algum lugar" (MRLEAU-PONTY 1966, 3). Talvez seja preciso interpretar este pensamento como expressão da dificuldade que o próprio filósofo encontrava para por em jogo os termos opostos da antinomia. A dificuldade da colocação em relação do particular e do universal é, enfim, a dificuldade comum a todos aqueles que procuram se exprimir de modo compreensível. É neste sentido que a questão do filósofo não está muito distante daquela de Cézanne ou do cidadão da época, pois

como Cézanne se pergunta se o que saiu de suas mãos oferece um sentido e será compreendido, como um homem de boa vontade, considerando os conflitos de sua vida, começa a duvidar que as vidas sejam compatíveis entre si, o cidadão de hoje não está seguro que o mundo humano seja possível. (MERLEAU-PONTY 1966, 10)

O que está em jogo nesta dúvida e que interessa tanto ao filósofo é o fato de que a universalidade envolve a particularidade. Eis aí a nova ideia de razão situada entre o sentido e o não-sentido. Mas precisamente por ser esta espécie de mistura, não há uma garantia absoluta do sucesso da empreitada. A começar pelos próprios criadores, mas também levando em consideração os homens da rua, em 1945, não se tinha a certeza de que aquilo que há de mais vivo e novo ainda seria suficiente para instaurar o mundo humano, apesar de que seria preciso imaginar alguém que desse um passo na bruma ensaiando e tentando uma aproxima- 
ção da comunicação: alguém que fizesse e comunicasse a experiência da instauração deste sentido precário e em estado nascente.

O Prefácio de Sentido e não-sentido nos lembra ainda que a situação no mundo sensível, na obra de arte, na ética e na matemática não é muito diferente. Nas matemáticas não há mais aquelas longas cadeias de razão: os seres matemáticos devem ser alcançados, agora, por processos oblíquos, métodos improvisados "tão opacos quanto um mineral desconhecido". Anteriormente se acreditava na superioridade de um mundo inteligível onde a claridade absoluta nos permitia conhecer o maior número de diferença entre coisas e significações. Agora, ao contrário, há núcleos irradiantes que são separados por telas escuras. Tanto o mundo da cultura quanto outrem que tradicionalmente aparecem ricos de uma continuidade perene, devem, finalmente, guardar lugar para uma descontinuidade movida por "surdas mutações". "Na obra de arte ou na teoria como na coisa sensível, o sentido é inseparável do signo. A expressão, por conseguinte, não é de modo algum acabada. A mais alta razão vizinha da desrazão" (MERLEAU-PONTY 1966, 8-9). É por aí que uma moral tal como pensa Merleau-Ponty deve ser reencontrada: em contato com os conflitos o agente deve assumir radicalmente o que ele é por acaso e realizar a comunicação. Assim, em qualquer ramo da cultura e do mundo sensível, não há solução para quem quer assegurar sua marcha e permanecer inteiramente justo e senhor absoluto de si mesmo. Enquanto filósofo, Merleau-Ponty se preocupa em evocar o "fundo de não-sentido sobe o qual delineia toda empreitada universal, e que a ameaça de impasse”. Resta que o recurso que temos a nossa disposição é o nosso próprio engajamento no "movimento espontâneo 
que nos liga aos outros para a tristeza e para a felicidade, no egoísmo e na generosidade" (MERLEAU-PONTY 1966, 9).

$\bigcirc$ risco descrito pelo filósofo consiste em que talvez não consigamos integrar os opostos que estão dissociados graças à divergência entre os representantes da cultura. Em um contexto como este é preciso perguntar, então, se há, de fato, um pensamento que não estabeleça alguma relação com a linguagem e com o corpo, assim como se torna imprescindivel investigar as relações da histórica com sua infraestrutura. Vem daí que a tarefa da filosofia ainda seja a de tratar do problema da universalidade, da razão, mas é preciso acrescentar a isto o fato de que a própria universalidade não está mais afastada da particularidade, assim como o sentido do não-sentido. ${ }^{6} \mathrm{O}$ preço a pagar ao assumir esta racionalidade alargada é alto: há que se abandonar a antiga razão estéril, séria, respeitável e definitiva, já que são as próprias pesquisas modernas que têm um "ar de improviso e de provisório", um "jeito meio desvairado" (MERLEAU. PONTY 1996, 190). Para Merleau-Ponty, o "impasse não é fatal. Cézanne ganhou contra o acaso. Os homens podem ganhar também, sob a condição de que eles avaliem o risco e a tarefa" (MERLEAU-PONTY 1966, 10). Parece-nos que a sugestão está em que Cézanne poderia nos servir de exemplo no que concerne ao pensamento e à ação, pois ele realizou, à sua maneira, a expressão e a comunicação.

\footnotetext{
${ }^{6}$ Lembremos que aquilo que Merleau-Ponty chama de existencialismo "se definiria talvez pela ideia de uma universalidade que os homens afirmam ou implicam, pelo simples fato de que eles existam e no momento mesmo em que eles se opõem, uma razão imanente à desrazão, uma liberdade que se torna o que ela é ao dar-se laços, e cuja menor percepção, o menor movimento do coração, a menor ação são testemunhas incontestáveis" (MERLEAU-PONTY 1966, 121).
} 


\section{IV - O CONCRETO}

Tematizando a noção de concreto temos a oportunidade de fazer alusão à intrincada relação entre o particular e o universal. Ao invés da tópica do conhecimento que procura explicar o mundo ou descobrir suas condições de possibilidade, tratar-se de reconhecer a validade de um ponto de vista em que o sentido não se desenraiza mais do mundo natural e cultural. Além disto, é preciso inventar maneiras de exprimir ou formular esta experiência do mundo. Para condensar ao máximo esta tendência da nova filosofia da época de abrir mão do encadeamento de conceitos para voltar-se em direção da descrição da mistura da consciência com o mundo, seu engajamento num corpo, sua coexistência com os outros, lembremos a palavra de ordem que comandava toda uma geração: em direção ao concreto. Este lema é, na verdade, o título de um livro publicado em 1932. ${ }^{7}$ A ideia por traz deste título tem como alvo principal todo um ensinamento tradicional que priorizava o sujeito epistemológico excluindo da filosofia qualquer possibilidade de tecer enunciados sobre o mundo. O lema desta velha escola era, precisamente, em direção ao espírito! Qual é, então, o sentido disto que foi chamado de concreto em filosofia? Seu significado deve ser procurado na afinidade, na convergência, ou ainda, na intersecção entre várias filosofias. Há, porém, o livro de Jean Wahl que influenciará a maioria dos filósofos contemporâneos, sobretudo, na França: Em direção ao concreto. Neste texto ele nos diz que "o concreto não será nunca um dado para o filósofo. Ele será o perseguido. Somente

\footnotetext{
${ }^{7}$ Vale observar que é apenas em 1951 que Émile Bréhier, um dos maiores representantes da filosofia oficial, nos diz que "é no movimento enérgico em direção ao concreto que é preciso procurar a origem da filosofia contemporânea” (BRÉHIER 1954, 76).
} 
na ausência do pensamento o concreto pode se revelar a nós" (WAHL 2004, 44). Dito de outro modo: o pensamento contemporâneo dirige o olhar do filósofo em direção a esta região da experiência anterior às relações do tipo científico e a partir da qual estas próprias relações são formadas. Portanto, voltar-se em direção ao concreto é ir contra o idealismo tradicional e reconhecer que há no pensamento contemporâneo "um esforço em direção de uma concepção inteiramente oposta ao kantismo e às investigações sobre a teoria do conhecimento" (WAHL 2004, 119). Que se perceba que não se trata de opor o particular ao universal, mas o concreto ao abstrato, tão característico do idealismo da velha escola da filosofia triunfante. ${ }^{8}$ Como sempre, trata-se de investigar aquilo que o idealista e a ciência não dizem ou se calam: os seus pressupostos. Para Jean Wahl, a ciência deve ser compreendida como um "instrumento de análise". Se procedermos assim, compreenderemos que o mundo não pode ser nem construído pela análise nem decomposto pela ciência: "há algo que resiste à análise". Ora, tudo muda quando "colocando nosso espírito no meio das coisas" descobrimos um "contato, um parentesco" entre o espírito e as coisas. Neste contexto, não há mais a antiga oposição entre a necessidade e a liberdade. $\mathrm{O}$ interessante está em que, doravante, passividade e atividade "devem sempre se completar”. Sartre dará um testemunho interessante a propósito deste livro que exprime um "envelhecimento da filosofia

\footnotetext{
${ }^{8}$ Gabriel Marcel publica um artigo com título sugestivo neste contexto: Esboço de uma filosofia concreta. Comentando o seu título, Marcel diz que "para alguns", este título poderia causar "escândalo", e observa, ainda no começo do texto, que "se a expressão 'filosofia concreta' tem algum sentido, é antes de tudo porque ela corresponde a uma recusa de princípio oposta a todos os 'ismos', oposta a certa escolarização". "O que é filosofar concretamente? Isto não quer dizer de forma alguma voltar ao empirismo; isto é capital. [...] Nós nos aproximaríamos muito da verdade dizendo que é filosofar hic et nunc" (MARCEL 1940, 82/85).
} 
francesa e uma necessidade que todos nós experimentávamos de rejuvenescê-la" (SARTRE 1983, 228):

um livro teve muito sucesso entre nós nessa época: Vers le concret, de Jean Whal: e ainda nos decepcionava este 'vers': é do concreto total que queríamos partir, é ao concreto absoluto que queríamos chegar. Mas a obra nos agradava porque embaraçava o idealismo, descobrindo paradoxos, ambiguidades, conflitos não resolvidos no universo. (SARTRE 1966, 21)

Referindo-se a Willian James, Alfred Whitehead e Gabriel Marcel, Jean Wahl nos diz que há na filosofia contemporânea o "mesmo culto da realidade em sua espessura”. Para tais filósofos, é preciso compreender as relações científicas em sua densidade própria, elas devem ser reconhecidas no próprio mundo. Esta dimensão relacional é, justamente, governada por leis de toda espécie, tais como as leis físicas, matemáticas, lógicas, biológicas e psicológicas. As leis expressas por essa dimensão relacional são relações que "traduzem alguma coisa, um fundo não-relacional e, todavia, unificante (se nós podemos empregar esta palavra sem que venha ao espírito a ideia de um ato da inteligência) que é compreendida nele" (WAHL 2004, 32). Este fundo não-relacional que para Merleau-Ponty, na esteira de Wahl, as ciências nos remetem, abre as portas para a nova filosofia e permite ao filósofo não estar mais ilhado em um território totalmente distinto do mundo e de suas questões. Não podemos, depois de rejeitar o dogmatismo, fazer de conta que as estruturas expressas pelas leis físicas, por exemplo, "bastassem para dar seu sentido ao campo temporal e espacial, como se o 'fundo não-relacional' sobre o qual se põem as relações estabelecidas pela física não entrasse na definição do conhecimento" (MERLEAU-PONTY 1990, 154). A ciência relaciona os dados da experiência e pressupõe tal 
"fundo não-relacional" como seu a priori, isto é, a própria condição da ciência. Este "fundo não-relacional", "a ciência pensa e não pensa”. Por um lado, ela pensa, ou melhor, ela opera uma determinação, uma fixação da experiência. Por outro lado, ela não pensa, já que o "fundo não-relacional" é o indeterminado, o impensado da determinação, aquilo a que a determinação reenvia, a saber, o mundo como pressuposto fundamental que cabe a filósofo explorar. Trata-se do mundo da percepção que não se reduz à construção ou à determinação científica, a qual termina sempre por nos reenviar, de novo, ao próprio mundo. $\mathrm{Ou}$, como diz MerleauPonty,

se refletimos sobre nossos objetos de pensamento e da ciência, no fim das contas, eles nos reenviam ao mundo percebido como terreno em que eles devem se aplicar. Não quero dizer que o mundo percebido, no sentido do mundo das cores e das formas, seja a totalidade de nosso universo. Há o mundo ideal ou cultural: não diminuí sua originalidade, só quis dizer que ele se faz ao rés do chão. (MERLEAU-PONTY 1996, 88)

Este mergulho da filosofia no mundo contingente vai contra a tradição intelectualista. Sartre foi um dos primeiros a protestar contra este pensamento abstrato. Este pensamento que transforma tudo em representação do espírito não permite o acesso ao concreto. Em um pequeno texto escrito em 1939, Sartre se dirige contra a filosofia digestiva do empirismo crítico, do neo-kantismo e também contra o psicologismo. Segundo ele, esta filosofia digestiva comia com os olhos: isto marca precisamente a ilusão comum ao realismo e ao idealismo, para os quais conhecer é comer.

A filosofia francesa, depois de cem anos de academicismo, permanece aí. Nós todos lemos Brunschvicg, Lalande e Meyerson, nós todos acreditamos que o Espírito-Aranha atraía as coisas para sua teia, cobria-as com sua baba branca e lentamente as deglutia, reduzia-as a 
sua própria substância. (SARTRE 1947, 29)

Qual a resposta de Sartre a esta filosofia digestiva? O título do texto responde: a intencionalidade tal qual descoberta por Husserl, ou seja, o reconhecimento da atividade da consciência, só que agora redescoberta no interior do próprio mundo contingente. Em suma: o que a fenomenologia ensinou através deste conceito foi não separar o pensamento e as coisas. Este pequeno artigo de Sartre conclui reconduzindo o leitor precisamente para o exterior, para o mundo vivido. Contra o pensamento insular fascinado pela vida espiritual, contra a postura intelectual que pauta a vida segundo regras abstratas, precisamos reconhecer que "tudo está fora, tudo, até nós mesmos. Não é em não sei qual retiro que nós nos descobrimos: é na estrada, na cidade, em meio à multidão, coisas entre as coisas, homens entre os homens" (SARTRE 1947, 29).

Há de se concluir daí que para a filosofia militante da geração de pensadores do pós-guerra a coordenação científica do dado não mostra como as coisas são feitas e a objetividade científica não esgota a existência. É preciso, na verdade, ter consciência do objeto e acompanhar suas articulações não no espírito, mas no mundo, no concreto, na experiência natural e histórica. Para esta geração trata-se de voltar para contingência como aquilo que há de mais essencial, e isto, a tal ponto que na esteira de Heidegger, Sartre dirá, em A náusea, romance filosófico publicado em 1938, que

o essencial é a contingência. Quero dizer que, por definição, a existência não é a necessidade. Existir é ser aí, simplesmente; os existentes aparecessem, se deixam encontrar, mas não podemos nunca deduzilos. [...] Nenhum ser necessário pode explicar a existência: a contingência não é uma ilusão, uma aparência que podemos dissipar; é o 
absoluto, consequentemente, a gratuidade perfeita. (SARTRE 1938, $185)^{9}$

Merleau-Ponty, por sua vez, vai procurar um espaço para se instalar que seja equidistante ao idealismo e ao realismo. $\mathrm{O}$ idealista não explora o mundo que está à margem da ciência, pois a filosofia é simplesmente atividade sobre o objeto da ciência. Contra o realismo, como não reconhecer a atividade da consciência? $\mathrm{O}$ mundo deve ser descrito por si mesmo, ele não é menos real do que a própria ciência. É neste sentido que a metafísica deve ser entendida como filosofia concreta, ou seja, o contrário de um sistema onde o arranjo dos conceitos tornaria compatíveis os aspectos da experiência através das relações estabelecidas formalmente. Para esta filosofia, a metafísica não é mais construção de conceitos abstratos; ela é, sim, a experiência que fazemos dos paradoxos nas situações individuais e coletivas. Não há resposta que anule tal experiência, mas somente respostas que a levam mais adiante: ela é a consciência da contingência.

A maneira através da qual as relações entre o particular e o universal são tematizadas no interior da filosofia do pósguerra difere de uma filosofia para outra. Uma vez que nosso objetivo aqui consistiu apenas em apreender um movimento teórico de conjunto comum a vários pensadores movimento que pode ser apreendido como um conjunto de

\footnotetext{
${ }^{9}$ É bem provável que Sartre faça, aqui, eco à frase de Heidegger em que ele o diz expressamente que "a 'essência' do Dasein reside na sua existência". (HEIDEGGER 1985, §9) Não se trata de negar a essência. Ao contrário, para Heidegger, o que está em questão é a interpretação da essência do homem, ou melhor, a sua definição. Portanto, não devemos mais opor essência e existência como faz a ontologia tradicional. Também não é o caso de dizer nem que a existência é algo que poderíamos constatá-la em algum lugar do espaço físico, nem lhe atribuir algumas propriedades, no caso, a essência. Em suma: o homem é essencialmente ser-no-mundo (ele não pode ser separado do mundo).
} 
tendências que vão em direção de uma transformação dos conceitos clássicos -, resta que a potencial divergência de base doutrinal existente na mudança de uma filosofia para outra, esta divergência não anula a convergência de horizonte presente na interrogação daquilo que é o concreto. No geral, o gesto teórico que consiste em voltar os olhos para o mundo não deve andar separado da compreensão do sentido da experiência como essencialmente temporal. Não há que se escolher entre os dois limites da experiência do tempo: fragmentação e insularidade. A aquisição da experiência e a liberdade só aparecem como contraditórios se perdemos de vista nossa inscrição natural e nosso horizonte cultural. Haverá comunicação entre os extremos se, por um lado, assumirmos nossa estrutura temporal e, por outro, se a liberdade for um esboço desta estrutura. Não é fora do mundo que a percepção e a cultura se realizam, não é de fantasmas que aguardamos o assentimento de nossas ações. A existência não deve ser compreendida separada do tempo. No contexto das filosofias que giram em torno da noção de existência, podemos dizer que somente a relação entre a subjetividade e a temporalidade pode lançar luz e exprimir a difícil implicação e permuta existente entre o particular e o universal. É verdade, encontramos os traços do concreto na existência efetiva que "atravessa o tempo sem o deixar". Mas como, enfim, reconhecer esta existência? Segundo Merleau-Ponty, trata-se de uma circunscrever uma "existência total" que é, precisamente, "a decisão através da qual entramos no tempo para nele criar nossa vida" (MERLEAU. PONTY 1966, 70). Apontando para as questões que giram entorno da problemática do tempo e da história, temos, então, alguma chance de vislumbrar o horizonte teórico desses discursos sobre o concreto. $O$ sentido da interrogação da 
noção de concreto em filosofia pode ser circunscrito desde que se tenha compreendido que ela exprime uma troca e uma permuta entre o fato e a essência. Mais ainda: através desta noção é preciso atribuir dignidade ontológica e fenomenal a esta tensão paradoxal que constitui a relação entre a particularidade e a universalidade.

Abstract: We shall place ourselves beside Merleau-Ponty's philosophy to shed light on the notion of concrete, which brings in it the fact and the essence, the particle and the universal, in doing so we shall be opposed to the theoretical attitude, named by Merleau-Ponty "small rationalism", of the early twentieth century. Firstly, we shall remember how the philosopher characterizes the theoretical attitude that reduces everything that can be said about the world to the scientific. After, we shall briefly insist upon the fact that this theoretical attitude is not far from a highly naif political attitude which is unaware of the world it belongs to. According to Merleau-Ponty, in order to understanding the rapports between the sense and the non-sense it is necessary a new conception of reason: not a reason which operates by concepts on the background of an unquestionable rationality, but a reason that considers its origins.

Keywords: Spirit; concrete; universal; particular.

\section{REFERÊNCIAS}

BEAUVOIR, Simone. La force des choses I. Paris: Gallimard, 1963.

BRÉHIER, Émile. Les thèmes actuels de la philosophie. Paris: Puf, 1954.

HEIDEGGER, Martin. Etre et temps. Tradução E. Martineau, Paris: Authentica, 1985.

LALANDE, André. Vocabulário técnico e crítico da filosofia. Tradução Fátima Sá Correia, São Paulo: Martins Fontes, 1999.

MARCEL, Gabriel. Ébauche d'une philosophie concrète. In: Du refus a l'invocation, Paris: Gal- 
limard, 1940.

MERLEAU-PONTY, Maurice. Signes. Paris: Gallimard, 1996.

. Sens et non-sens. Paris: Nagel, 1966.

. Parcours II. Verdier: Lagrasse, 2001.

. La structure du comportement. Paris : Puf,

1990.

- Le primat de la perception et ses conséquences philosophiques. Verdier: Lagrasse, 1996.

SARTRE, Jean-Paul. Questões de método. São Paulo: Difusão Européia do Livro, 1966.

. Une idée fondamentale de la phénoménologie de Husserl: l'intencionalité. In: Situation I, Paris: Gallimard, 1947.

. La nausée. Paris: Gallimard, 1938.

. Les carnets de la drôle de guerre. Novembre 1939-Mars 1940. Paris: Gallimard, 1983.

WAHL, Jean. Vers le concret. Études d'histoire de la philosophie contemporaine (William James, Whitehead, Gabriel Marcel). Paris: Vrin, 2004.

WORMS, Frédéric. Le moment 1900 en philosophie. Paris: Septentrion, 2004.

. La philosophie en France au XXe siècle. Moments. Paris: Gallimard, 2009. 